Research Article

\title{
Design and Analysis of a Rectangular Fin with Comparing by Varying Its Geometry and Material, With Perforation and Extension
}

\author{
Kota LeelaSaiBharath ${ }^{1}$,V Pradeep Kumar ${ }^{2}$ \\ ${ }^{1}$ M.Tech(CAD/CAM) Scholar Dept of Mechanical Engineering Avanthi Institute Of \\ Engineering \& Technology \\ ${ }^{2}$ Associate Professor Dept of Mechanical Engineering Avanthi Institute Of Engineering \& \\ Technology
}

Article History: Received: 11 January 2021; Accepted: 27 February 2021; Published online: 5 April 2021

\begin{abstract}
Extending fins improve the rate of heat transfer or decrease convection. A fin is only for the reason of increasing the surface area in order to maximize heat transmission like a motor, heat exchanger, CPU, or to a heat-generating surface area. The benefit of performing thermal analysis on a flat fin is that it will tell how far heat is dissipated. This paper's primary purpose is to design and evaluate the thermal properties of rectanglular fin with varying geometry and content, and to expand the rectangular fin plate with Catia5R tools. Catia and Ansys are used to construct the geometries, and analyses of thermal properties are applied to them The tip is $5 \mathrm{~mm}$ wide at present, decreased to $4 \mathrm{~mm}$. The aluminum alloy used in the manufacture of the rectangular fin body has thermal conductivity of $110-160 \mathrm{mK}$. The conducting coating on this paper is replaced with Aluminum Alloy 1100, which has a thermal conductivity of 210 to the $\mathrm{mW} / \mathrm{mk}$ for the substrate and many unusual and prolonged margins. Case studies are used and graphed as well as total conclusions are drawn.
\end{abstract}

Keywords -rectangular plate, geometry, material, perforations, extended fins, Catiav5R19, Ansys workbench15.0, Temperature distribution, total heat flux etc.

\section{Introduction}

Abdullah, H. Alessaet. al. [1] had studied the natural convection heat transfer enhancement from a horizontal rectangular fin embedded with equilateral triangular perforations. The heat dissipation rate from the perforated fin is compared to that of the equivalent solid one. The effect of geometrical dimensions of the perforated fin and thermal properties of the fin was studied in detail. They concluded that, for certain values of triangular dimensions, the perforated fin can result in heat transfer enhancement. The magnitude of enhancement is proportional to the fin thickness and its thermal conductivity. The perforation of fins enhances heat dissipation rates and at the same time decreases the expenditure of the fin material.

G. Babu, M. Lavakumar.[2] Heat Transfer Analysis and Optimization of Engine Cylinder Fins of Varying Geometry and Material in this paper the main aim of the project is to analyse the thermal properties by varying geometry, material and thickness of cylinder fins. Parametric models of cylinder with fins have been developed to predict the transient thermal behaviour. The models are created by varying the geometry, rectangular, circular and curved shaped fins and also by varying thickness of the fins.

\section{Literature survey}

L.Prabhu[3].Heat transfer performance of fin is analysed by ANSYS workbench for the design of fin with various design configuration such as cylindrical, square and rectangular configuration. The heat transfer performance of fin with same base temperature is compared. In this thermal analysis, Aluminium was used as the base metal for the fin material. Fins are design with the help of CATIA V5R16. Analysis of fin performance done through the software ANSYS 15.0.

S.Jamala Reddy, Y.Tejeswar [4]. Design and Thermal Analysis of Cooling Fins by Varying its Geometry and Material in this paper. The main purpose of using these cooling fins is to cool the engine cylinder by air. The main aim of the project is to analyse the thermal properties by varying geometry, material and thickness of cylinder fins. Transient thermal 
analysis determines temperatures and other thermal quantities that vary over timeZanWU[5]. Natural convection heat transfer enhancement of perforated fin array with different perforation diameter 4-12mm and a different Angles of inclination (0-90) increase in the heat transfer coefficient was achieved with perforated fins of $12 \mathrm{~mm}$ perforation diameter of the Angle of orientation 45 degree which shows about $32 \%$ enhanced heat transfer coefficient with saving $30 \%$ material.

PardeepSingh [5] In this research, the heat transfer performance of fin is analysed by design of fin with various extensions such as rectangular extension, trapezium extension, triangular extensions and circular segmental extensions. The heat transfer performance of fin with same geometry having various extensions and without extensions is compared. Near about ranging $5 \%$ to $13 \%$ more heat transfer can be achieved with these various extensions on fin as compare to same geometry of fin without these extensions. Fin with various extensions design with the help of software AutoCAD. Analysis of fin performance done through the software Autodesk Simulation Multiphysics. In this thermal analysis, temperature variations with respective to the distance at which heat flow occur through the fin is analysed. Extensions on the finned surfaces is used to increases the surface area of the fin in contact with the fluid flowing around it. So, as the surface area increase the more fluid contact to increase the rate of heat transfers from the base surface as compare to fin without the extensions provided to it. On comparison, rectangular extensions provide on fin gives the greatest heat transfer than that of other extensions having the same length and width attached to finned surface

The Fin allows heat flow rapidly by increasing the fineness of the device. to assist in heat transfer, fins are used on the device to further reduce the temperature in order to a manageable levels Thermal analysis on fins will reveal the amount of heat transfer and rate of dissipation for each form of fin. The three categories of fins are: Type "A: Inclined, Tapered, Type "C: Round, and Type "D: The use of fins will increase the rate of heat transfer to the material, or from the atmosphere through convection. the volume of heat transferred is a feature of the amount of conduction, convection, or radiation. Any of these methods may be used to maximize the heat transfer coefficient between the target and the atmosphere. More frequently than not, if any of the first two methods don't work, one has to be changed. Adding a fin expands the surface region, which is sometimes a cost-effective method for transferring heat.

The use of extensions improves the fin's interaction with the moving fluid field. If the surface area rises, fluid interaction with the foundation enhances heat transfer. folding like (a)

Trapezoidal, (b)L-shaped, (c) round, and (d)Helical extending.

One of the cheapest and most effective ways to get rid of unnecessary heat is to use fins. A rectiligne, conical, and dish shapes are the most common shapes because of fins due to their low manufacturing costs and superior thermal efficiency

One of the variables influencing the heat transmission rate is the wind direction, the other factors are the form of the turbine, the area of the exterior, and the temperature. In this study, conduction and convection aren't taken into account as it is performed on rectangular surfaces.

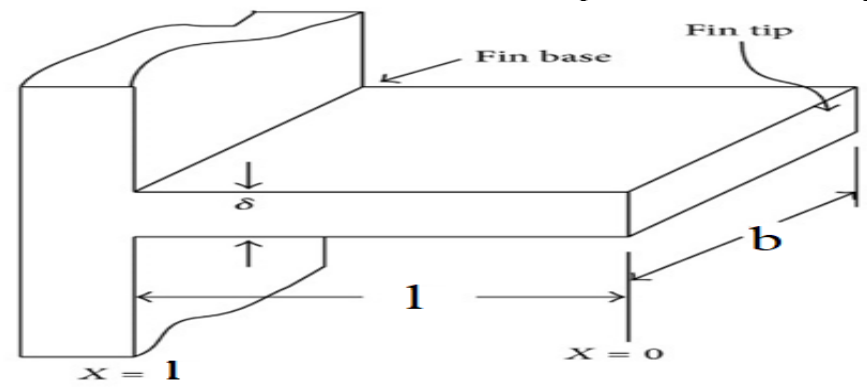

Fig 1. Basic Rectangular Fin 
A heatsink absorbs heat passively. A heat sink is usually takes the shape of a metallic component and is used to dissipate heat into a fluid to keep the system from becoming too hot.

\section{PROBLEM DEFINATION.}

The heat produced inside the device is to sustain a steady state. In large amounts, heat is transmitted by convection between the fluid surrounding the surface and the material. Metal strips may be attached to the surface of the device to maximize the surface area. But if these results are followed, the model of the fin will be changed, not only in different shape and scale, but also in many other ways.

\section{OBJECTIVES}

1. To form/utilize the varying fin/perfor geometries, content, and edge extension to enable experimental data collection,Conduct experiments on the rate of heat transfer in different situations.

2. To run a finite element study to analyze heat conductivity of the fin structures

3. Aluminium alloys are used in the manufacturing of the fins.

4. The geometric form of the tail is intended to show the transfer of heat characteristics

\section{METHODOLOGY} plate

1Step 1: Gather details and knowledge on the rectangular fin and geometry of a rectangular

Step 2:TheEngineplate with fins parametric model is ready in Catia.

Step 3: ANYS is used to retrieve the heat flux model in Step 2, and determine the thermal gradient.

Thus, in the final phase, we carry out various analyses, including ANS and hand measurements, for content, thickness, perforation, and extended surface to compare them.VI.FEM OF A FIN

In the present work, the software ANSYS 15.0 has been used to model and simulate Heat transfer and CFD analysis of heat sink with different cases in the fins.

A. Preparation of the Design model

The models of fins were generated in the CATIA V5 R21 release in the IGS (Intelligent Grids for Scientific Computing) format. The three-dimensional illustration of Figures [as is normally done in these kinds of diagrams].

This is a $60 \mathrm{~mm}$ (height) $\times 40 \mathrm{~mm}$ (width) x $5 \mathrm{~mm}$ (thickness) flat platform in all types of machines. For all versions, a fin height of $25 \mathrm{~mm}$ is defined. Analysis is attempted to be conducted on these products. Each fin has a different thickness, ranging from $5 \mathrm{~mm}$ to $4 \mathrm{~mm}$.

is close to that of a rectangle in that the diagonals cumulative length is equivalent to the length on a baseline $(60 \times 25 \mathrm{~mm})$.

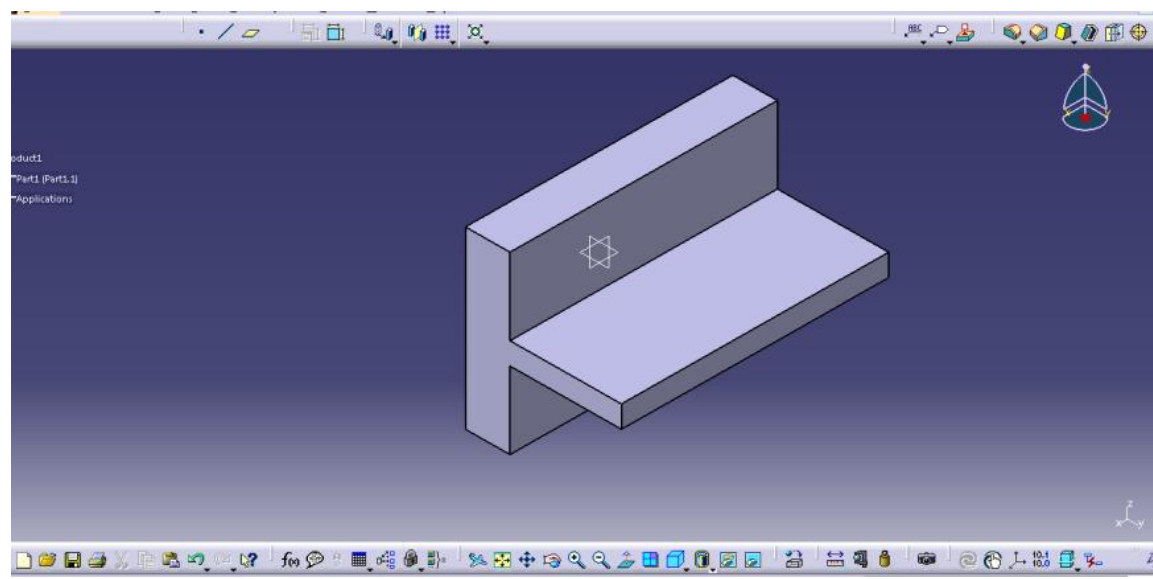

Fig 1. Rectangular Fin 
- Rectangular Fin and for varying material case: - The cross-sectional area of fin is (60 $\mathrm{x} 25 \mathrm{~mm})$.

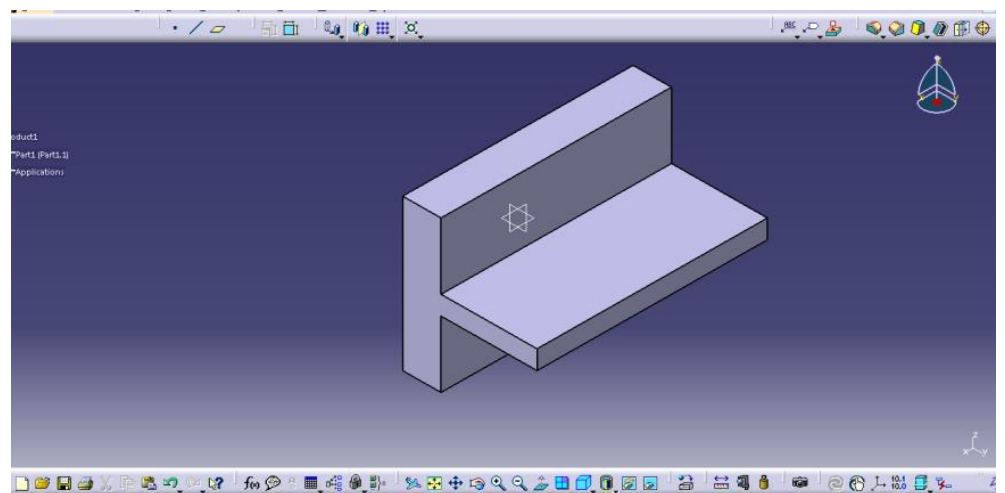

Fig 2. Rectangular Fin.

$25 \mathrm{~mm})$

- Rectangular Fin with varying thickness: -The cross-sectional area of fin is $(60 \mathrm{x}$

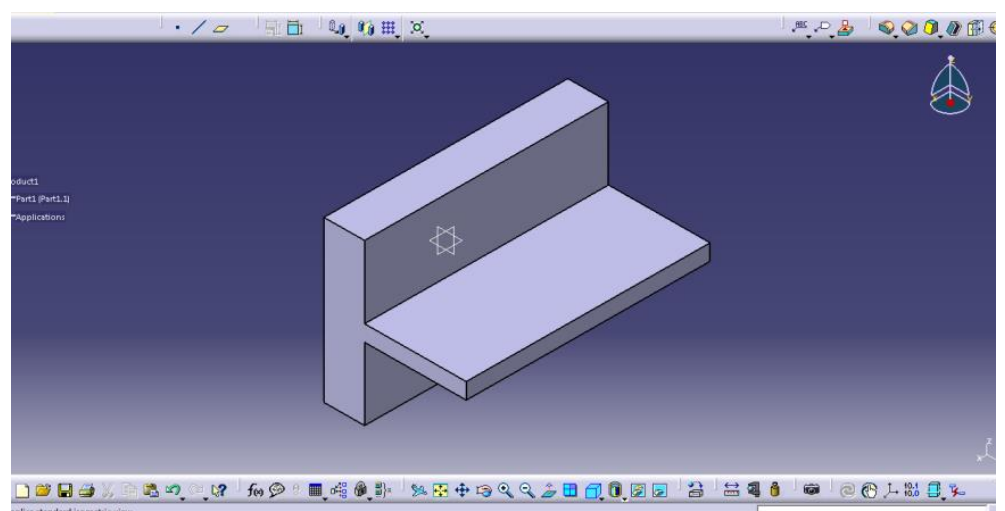

Fig 3. Rectangular Fin with varying thickness.

$25 \mathrm{~mm})$

- Rectangular Fin with rectangle perforation: - The cross-sectional area of fin is $(60 \mathrm{x}$

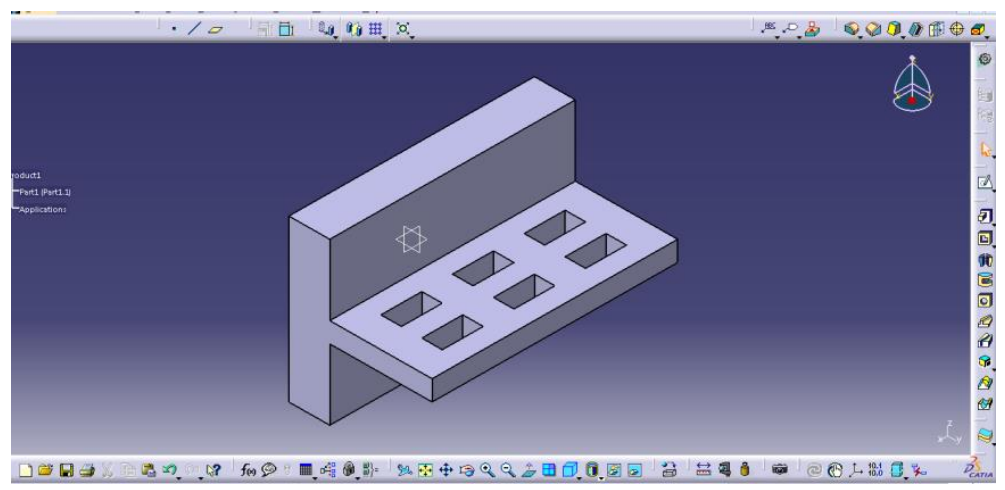

Fig 4. Rectangular Fin with rectangle perforation.

$25 \mathrm{~mm})$

- Rectangular Fin for rectangle extension: - The cross-sectional area of fin is $(60 \mathrm{x}$ 
Design and Analysis of a Rectangular Fin with Comparing by Varying Its Geometry and Material, With Perforation and Extension

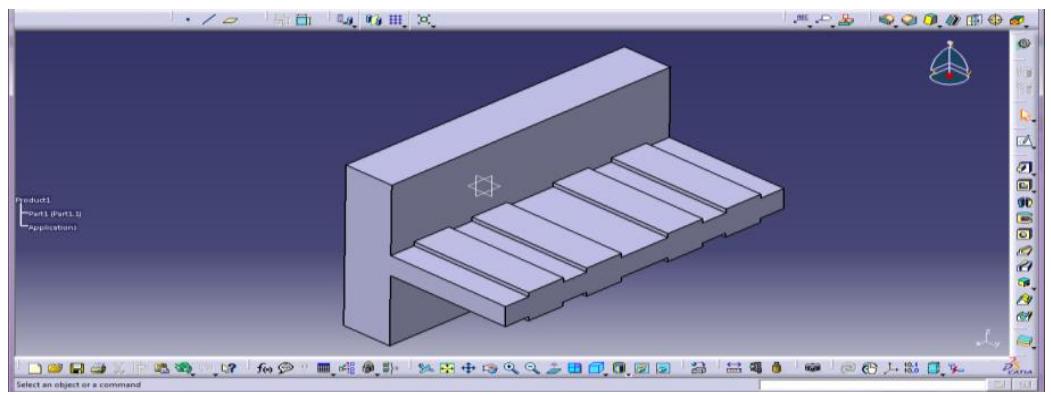

Fig 5. Rectangular Fin for rectangle extension

- Rectangular variable Fin: -The cross-sectional area of fin is $(60 \times 25 \mathrm{~mm})$

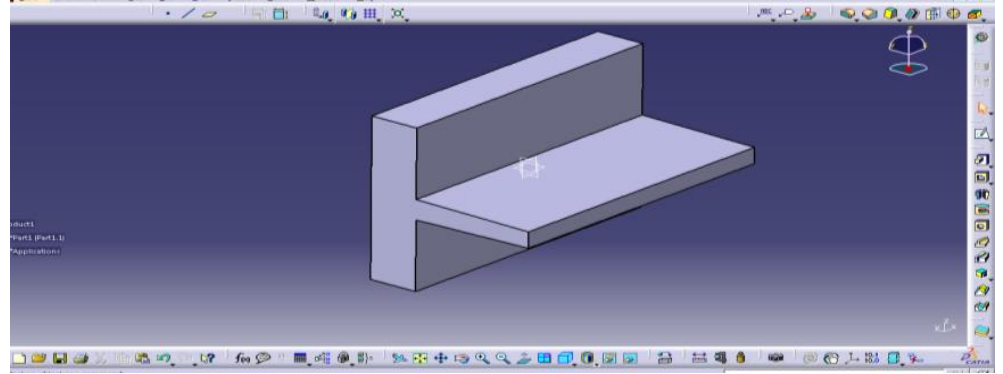

Fig7. Variable Rectangular Fin

\section{B. Geometry}

The detailed specifications of the fin design are shown in the below Fig 6. The material properties for modelling of the heat sink with perforated fin are shown in the Table and properties of air are tabulated

- Material: Aluminium

- Material Properties required for Analysis

- Density: $2.7 \mathrm{~g} / \mathrm{cc}$

- Youngs Modulus: $68.3 \mathrm{GPa}$

- Poisson's Ratio: 0.3

- $\quad$ Shear Modulus: $30 \mathrm{GPa}$

\begin{tabular}{|c|c|c|c|}
\hline & A & B & c \\
\hline 1 & Property & Value & Unit \\
\hline 2 & Z Density & 2770 & $\mathrm{~kg} \mathrm{~m}^{\wedge}-3$ \\
\hline 3 & B Isotopic Secant Coefficient of Thermal Expansion & & \\
\hline 4 & Coefficent of Thermal Expansion & $2.3 E-05$ & $c^{\wedge}-1$ \\
\hline 5 & B 7 Isotropic Elastoty & & \\
\hline 6 & Derive from & Young's Modius and Poisson's Rato & \\
\hline 7 & Young's Modulus & $7.1 E+10$ & $\mathrm{~Pa}$ \\
\hline 8 & Poisson's Ratio & 0.33 & \\
\hline 9 & Buk Modilus & $6.9608 E+10$ & $\mathrm{~Pa}$ \\
\hline 10 & Shear Moduius & $2.6692 \mathrm{E}+10$ & $\mathrm{~Pa}$ \\
\hline 11 & If OA SNarve & 1] Tabular & \\
\hline 15 & Z7 Tensile Yield Strength & $2.8 E+08$ & $p_{a}$ \\
\hline 16 & 7 Compressive Yield Strength & $2.8 E+08$ & $\mathrm{~Pa}$ \\
\hline 17 & Z7. Tensie Ultmate Strength & 3. $1 E+08$ & $\mathrm{~Pa}$ \\
\hline 18 & Compressive Utimate Strength & 0 & $\mathrm{~Pa}$ \\
\hline 19 & I Isotropic Thermal Conductvity & 1] Tabular & \\
\hline 20 & Scale & 1 & \\
\hline 21 & Offset & 0 & $W m^{\wedge}-1 C^{\wedge}-1$ \\
\hline 22 & 20 Specificheat, $C_{0}$ & 875 & $J \mathrm{~kg} \wedge-1 \mathrm{C}^{\wedge}-1$ \\
\hline 23 & If Isotropic Relative Permeability & 1 & \\
\hline 24 & If Isotopic Resistivity & 1] Tabular & \\
\hline
\end{tabular}

Fig 6. Material properties for analysis 


\section{Mesh Generation \& Simulation}

The fin model is imported in to the work bench design modeler and meshed as shown in the below figure- 3.4

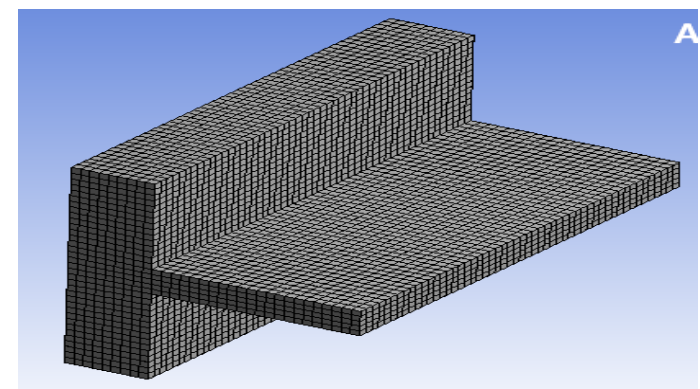

Fig 7. Mesh generation

D.Finite Element Model - Thermal Boundary Conditions

- Analysis Settings

- Convective Boundary condition of $30 \mathrm{~W} / \mathrm{m}^{2}$ heat transfer coefficient. Temperature of wall surface at which fin attached, to $=300{ }^{\circ} \mathrm{C}$ Ambient temperature, ta $=25{ }^{\circ} \mathrm{C}$

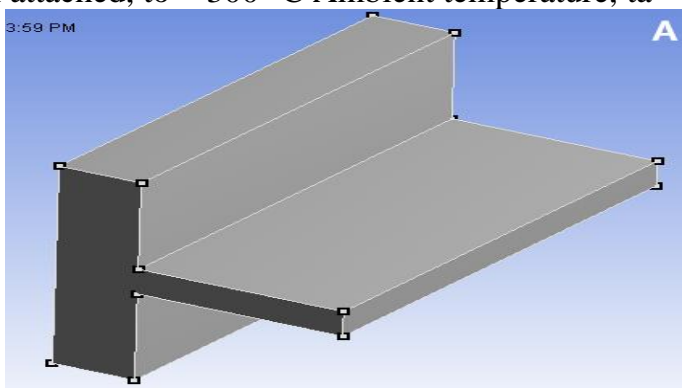

Fig 8. Finite element model

\section{RESULT AND DISCUSSION}

1)Rectangular fin - Al 6061

- $\quad$ Results - Temperature Gradient - Normal Fin

The temperature gradient is observed to be between 288.81 degrees and 300 degrees Celsius.

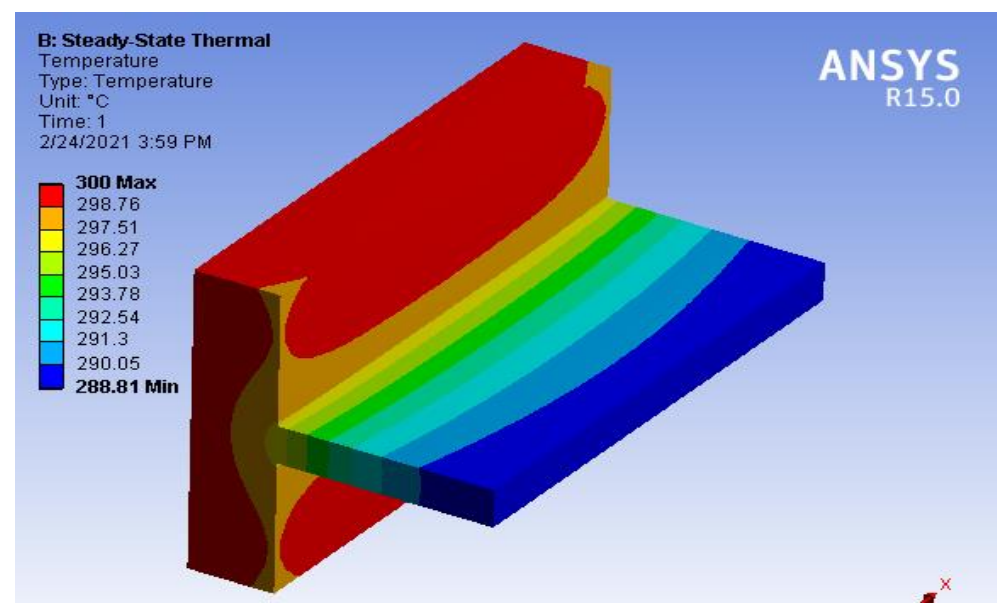

Fig 9. Temperature gradient of normal fin

- $\quad$ Results - Heat Flux Dissipation - Normal Fin 
Design and Analysis of a Rectangular Fin with Comparing by Varying Its Geometry and Material, With Perforation and Extension

The heat flux dissipation through the structure is observed to be $1.368 \mathrm{e} 5 \mathrm{~W} / \mathrm{m}^{2}$.

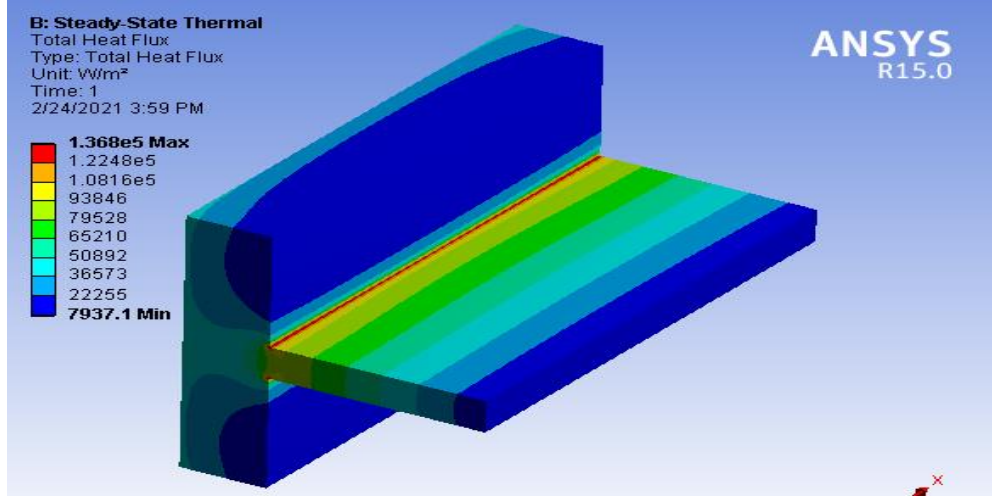

Fig 10. Heat flux dissipation of normal fin

2)Rectangular fin - Varying material Al 1100

- $\quad$ Results - Temperature Gradient - Rectangle Fin Varying Material

The temperature gradient is observed to be between 291.41 degrees and 300 degrees Celsius.

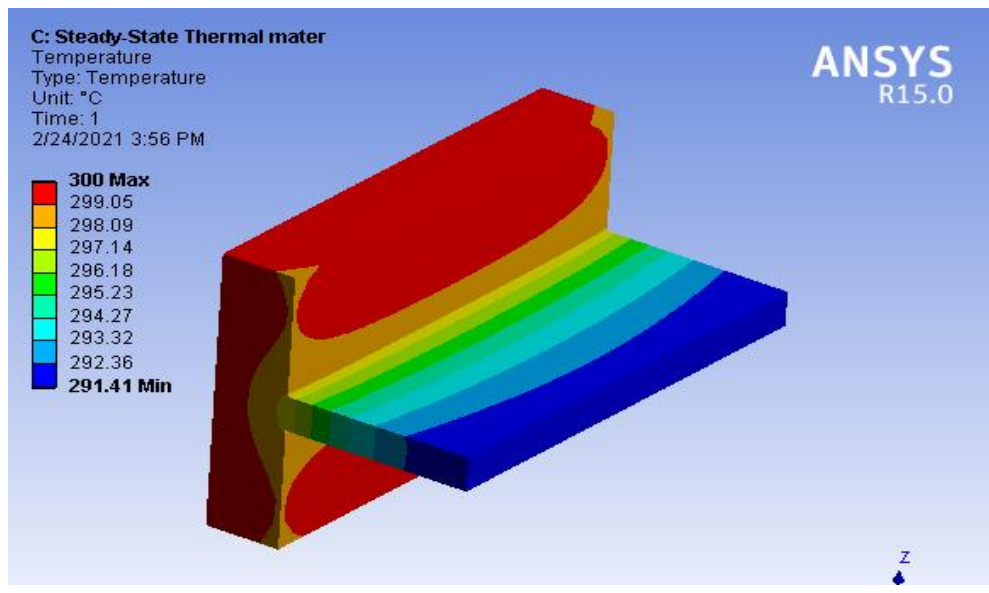

Fig 11. Temperature gradient of rectangle fin varying material

- $\quad$ Results - Heat Flux Dissipation - Rectangle Fin Varying Material

The heat flux dissipation through the structure is observed to be $1.3782 \mathrm{e} 5 \mathrm{~W} / \mathrm{m}^{2}$.

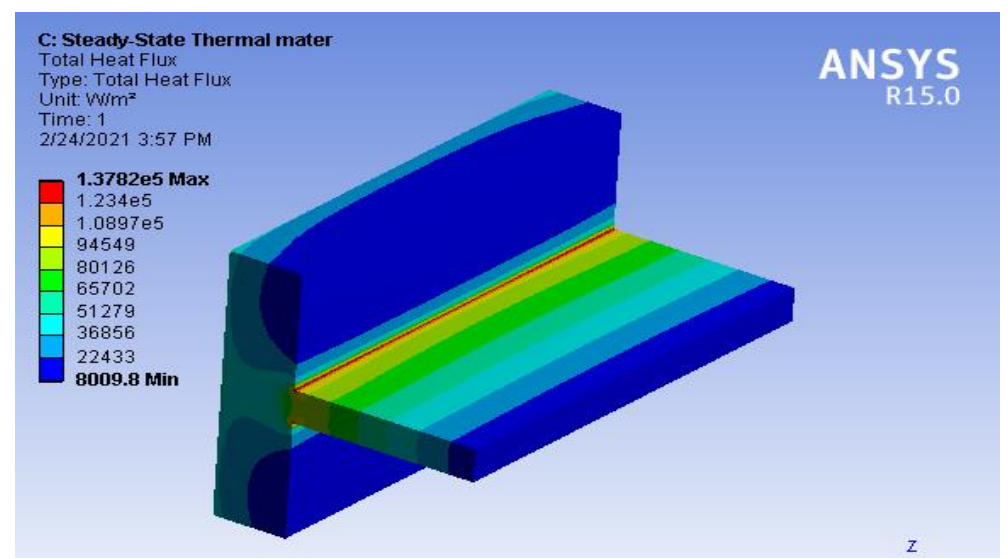

Fig 13. Heat flux dissipation of Rectangle Fin Varying Material 
3)Rectangular fin with varying thickness

- $\quad$ Results - Temperature Gradient - Rectangle Fin Varying Thickness Celsius.

The temperature gradient is observed to be between 287.17 degrees and 300 degrees

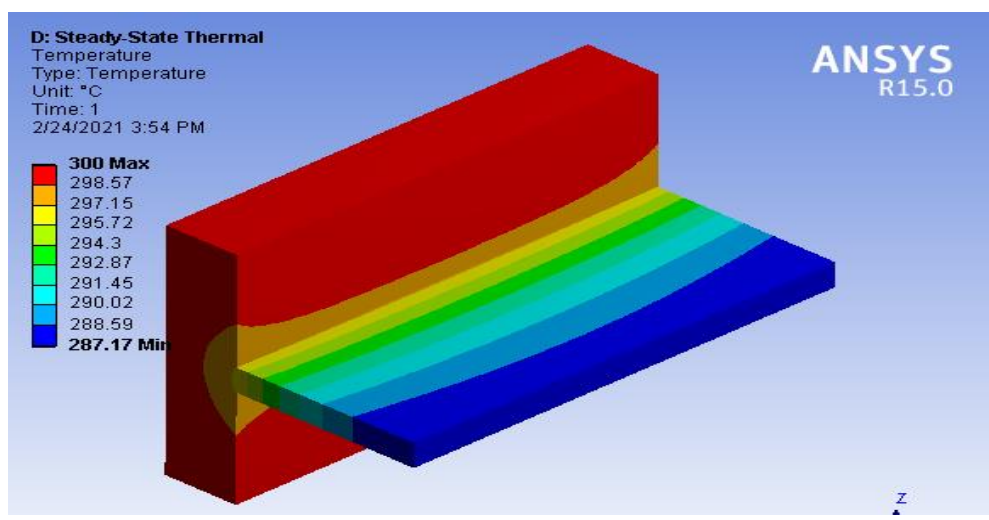

Fig 14. Temperature gradient of Rectangle Fin Varying Thickness

- $\quad$ Results - Heat Flux Dissipation - Rectangle Fin Varying Thickness

The heat flux dissipation through the structure is observed to be $1.72 \mathrm{e} 5 \mathrm{~W} / \mathrm{m}^{2}$

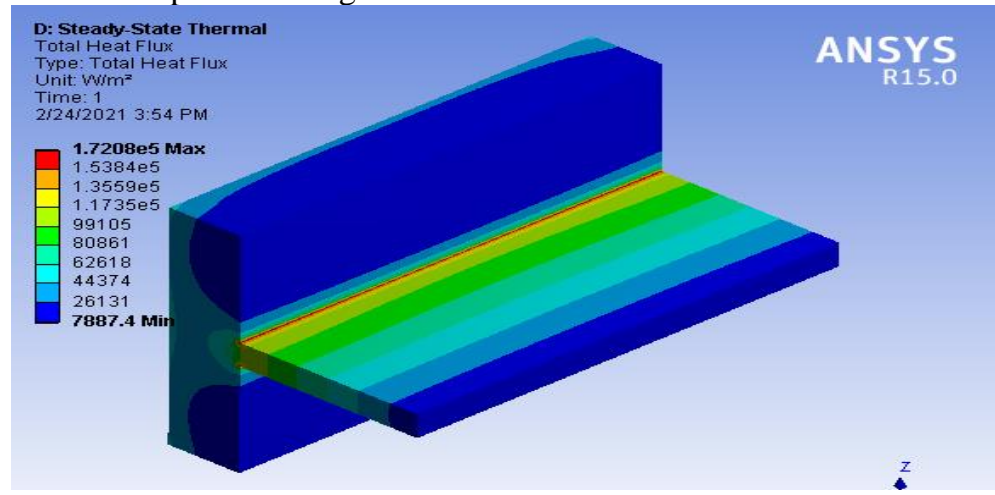

Fig 15. Heat flux dissipation of rectangle fin varying thickness

4)Rectangular Fin with Rectangle perforation

- $\quad$ Results - Temperature Gradient - Rectangle Fin with Rectangle perforation Celsius.

The temperature gradient is observed to be between 281.99 degrees and 300 degrees

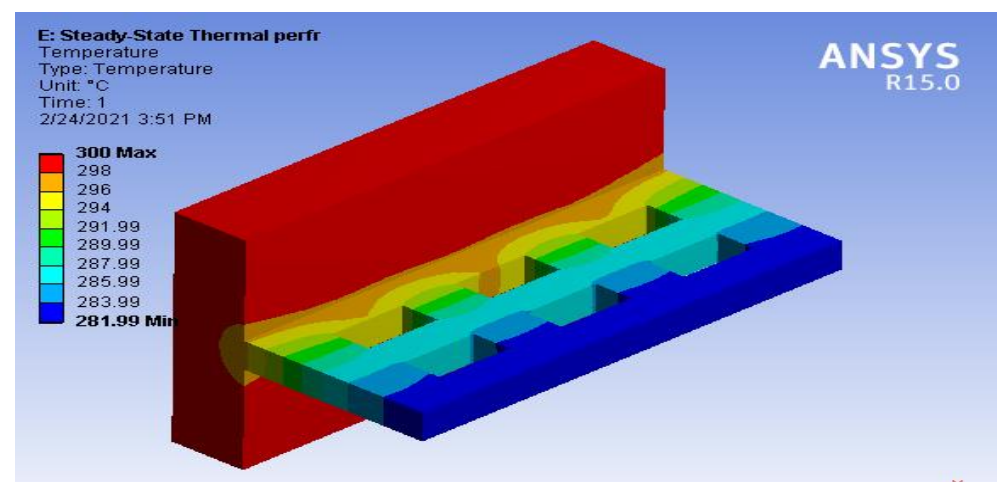

Fig 16. Temperature gradient of rectangle fin with rectangle perforation

- $\quad$ Results - Heat Flux Dissipation - Rectangle Fin with Rectangle perforation 
Design and Analysis of a Rectangular Fin with Comparing by Varying Its Geometry and Material, With Perforation and Extension

The heat flux dissipation through the structure is observed to be $2.53771 \mathrm{e} 5 \mathrm{~W} / \mathrm{m}^{2}$.

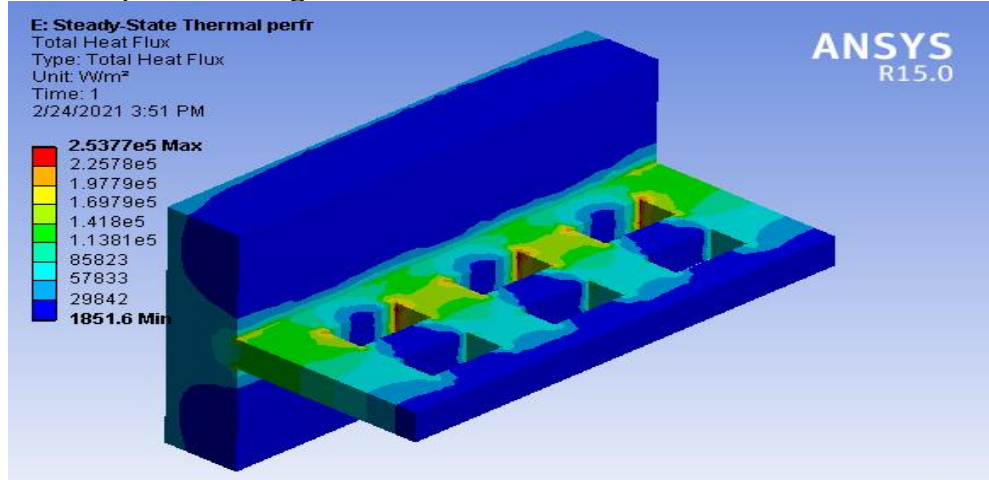

Fig 17. Heat flux dissipation of Rectangle Fin with Rectangle perforation

5) Rectangular Fin with Rectangle Extended surface

- $\quad$ Results - Temperature Gradient - Rectangle Fin with Rectangle Extended surface

The temperature gradient is observed to be between 289.2 degrees and 300 degrees Celsius.

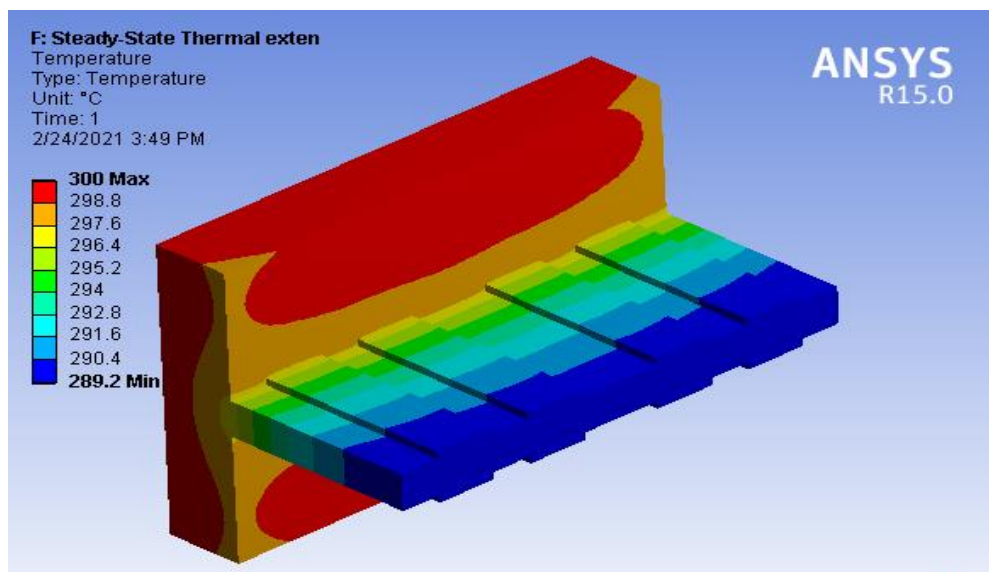

Fig 16. Temperature gradient of rectangle fin with rectangle extended surface

- Results - Heat Flux Dissipation - Rectangle Fin with Rectangle Extended surface The heat flux dissipation through the structure is observed to be $1.373 \mathrm{e} 5 \mathrm{~W} / \mathrm{m}^{2}$.

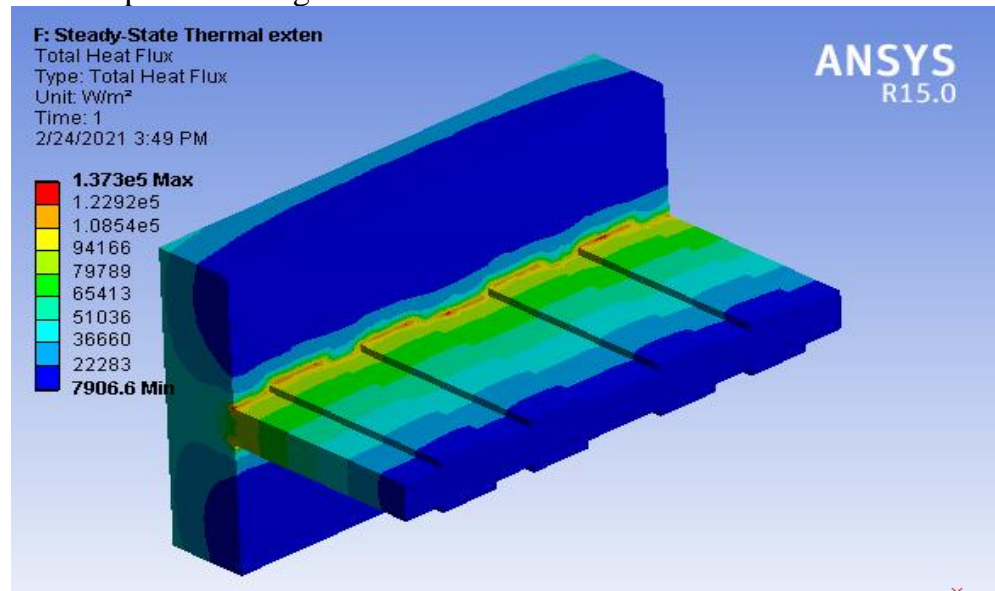

Fig 17. Heat flux dissipation of rectangle fin with rectangle extended surface 6) Variable Rectangle Fin

- $\quad$ Results - Temperature Gradient - Variable Rectangle Fin 
The temperature gradient is observed to be between 288.59 degrees and 300 degrees Celsius.

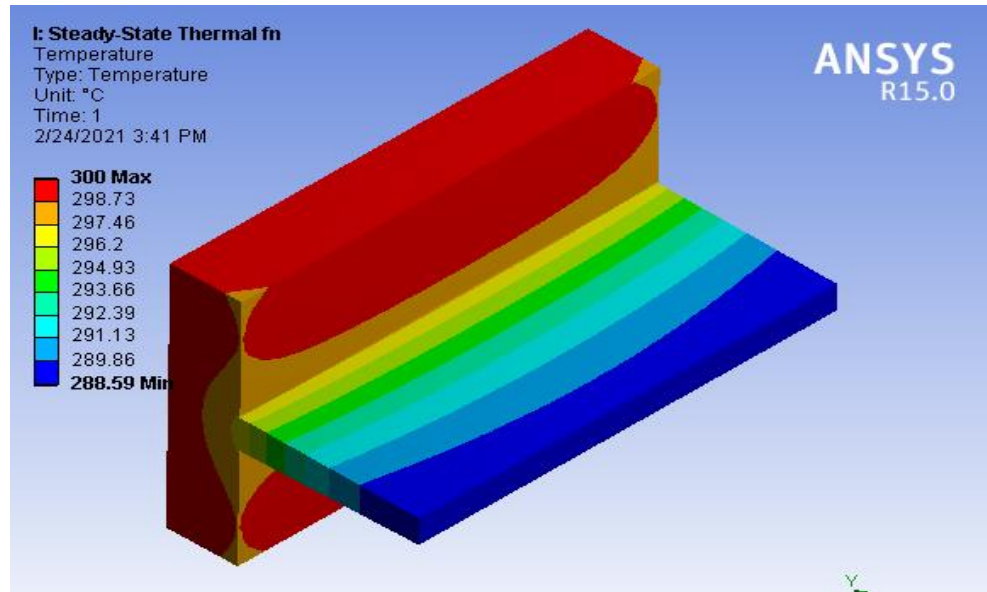

Fig 16. Temperature gradient of Variable Rectangle Fin

- $\quad$ Results - Heat Flux Dissipation - Variable Rectangle Fin

The heat flux dissipation through the structure is observed to be $1.3249 \mathrm{e} 5 \mathrm{~W} / \mathrm{m}^{2}$.

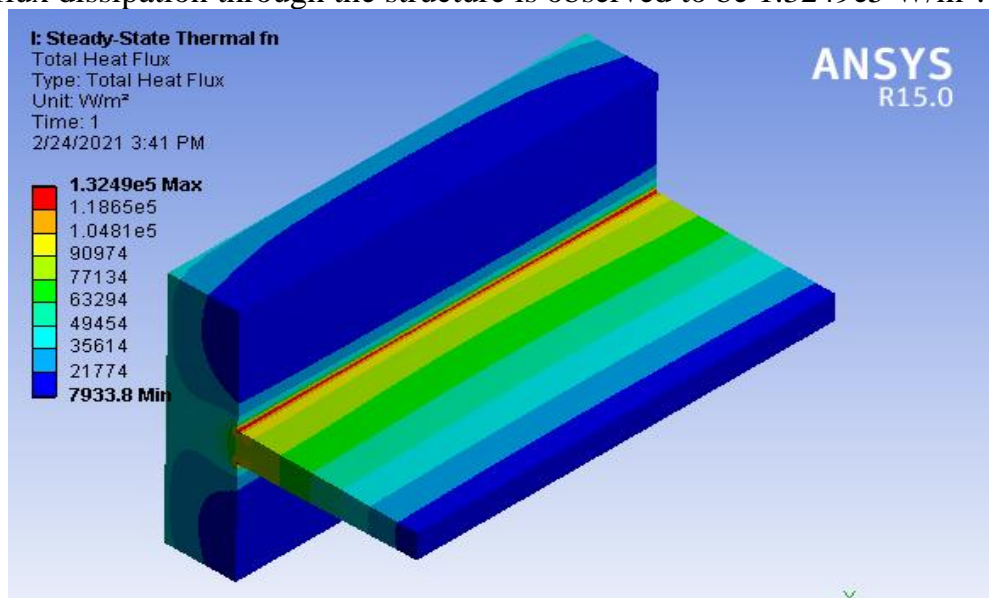

Fig 17. Heat flux dissipation of Variable Rectangle fin

\section{ADVANTAGE}

- Without intermediate impedance, thermal conductivity is good because the cutting tooth density is big, so the unit volume heat dissipation area is bigger.

- Standard in size and can be put into mass production.

- $\quad$ Light in weight.

- Solderable

- $\quad$ Customize relatively easy in vary of shapes

\section{DISADVANTAGES}

- Tooling and tooling fee, it's hard to satisfy small quantity order.

\section{RESULTS}

From the following tabulation the following graphs are drawn and the comparison is carried out for different cases of rectangular fin. The comparison is carried out for, temperature gradient and total heat flux. 
Design and Analysis of a Rectangular Fin with Comparing by Varying Its Geometry and Material, With Perforation and Extension

\begin{tabular}{|c|c|c|c|}
\hline S.n & Fin Type & $\begin{array}{l}\text { Maximum } \\
\text { temperature in }{ }^{\circ} \mathrm{C}\end{array}$ & $\begin{array}{l}\text { Minimum } \\
\text { temperature obtained in } \\
{ }^{\circ} \mathrm{C}\end{array}$ \\
\hline 1. & Normal rectangular fin & 300 & 288.81 \\
\hline 2. & $\begin{array}{c}\text { Rectangular fin } \\
\text { varying material }\end{array}$ & 300 & 291.41 \\
\hline 3. & $\begin{array}{c}\text { Rectangular } \\
\text { varying thickness }\end{array}$ fin $\quad$ with & 300 & 287.17 \\
\hline 4. & $\begin{array}{l}\text { Rectangular fin with } \\
\text { rectangle perforation }\end{array}$ & 300 & 281.99 \\
\hline 5. & $\begin{array}{c}\text { Rectangular fin with } \\
\text { rectangle extension }\end{array}$ & 300 & 289.2 \\
\hline 6. & Variable rectangular fin & 300 & 288.59 \\
\hline \multicolumn{4}{|c|}{ Table 1: - Maximum and Minimum temperature values of all fins } \\
\hline S.no & \multicolumn{2}{|c|}{ Fin Type } & Total heat flux in W/m² \\
\hline 1. & \multicolumn{2}{|c|}{ Normal rectangular fin } & $1.368 \mathrm{e} 5 \mathrm{~W} / \mathrm{m}^{2}$ \\
\hline 2. & \multicolumn{2}{|c|}{ Rectangular fin with varying material } & $1.3782 \mathrm{e} 5 \mathrm{~W} / \mathrm{m}^{2}$ \\
\hline 3. & \multicolumn{2}{|c|}{ Rectangular fin with varying thickness } & $1.72 \mathrm{e} 5 \mathrm{~W} / \mathrm{m}^{2}$ \\
\hline 4. & \multicolumn{2}{|c|}{ Rectangular fin with rectangle perforation } & $2.53771 \mathrm{e} 5 \mathrm{~W} / \mathrm{m}^{2}$ \\
\hline 5. & \multicolumn{2}{|c|}{ Rectangular fin with rectangle extension } & $1.373 \mathrm{e} 5 \mathrm{~W} / \mathrm{m}^{2}$ \\
\hline 6. & \multicolumn{2}{|c|}{ Variable rectangular fin } & $1.3249 \mathrm{e} 5 \mathrm{~W} / \mathrm{m}^{2}$ \\
\hline
\end{tabular}

Table 2: - Heat flux values of all fins

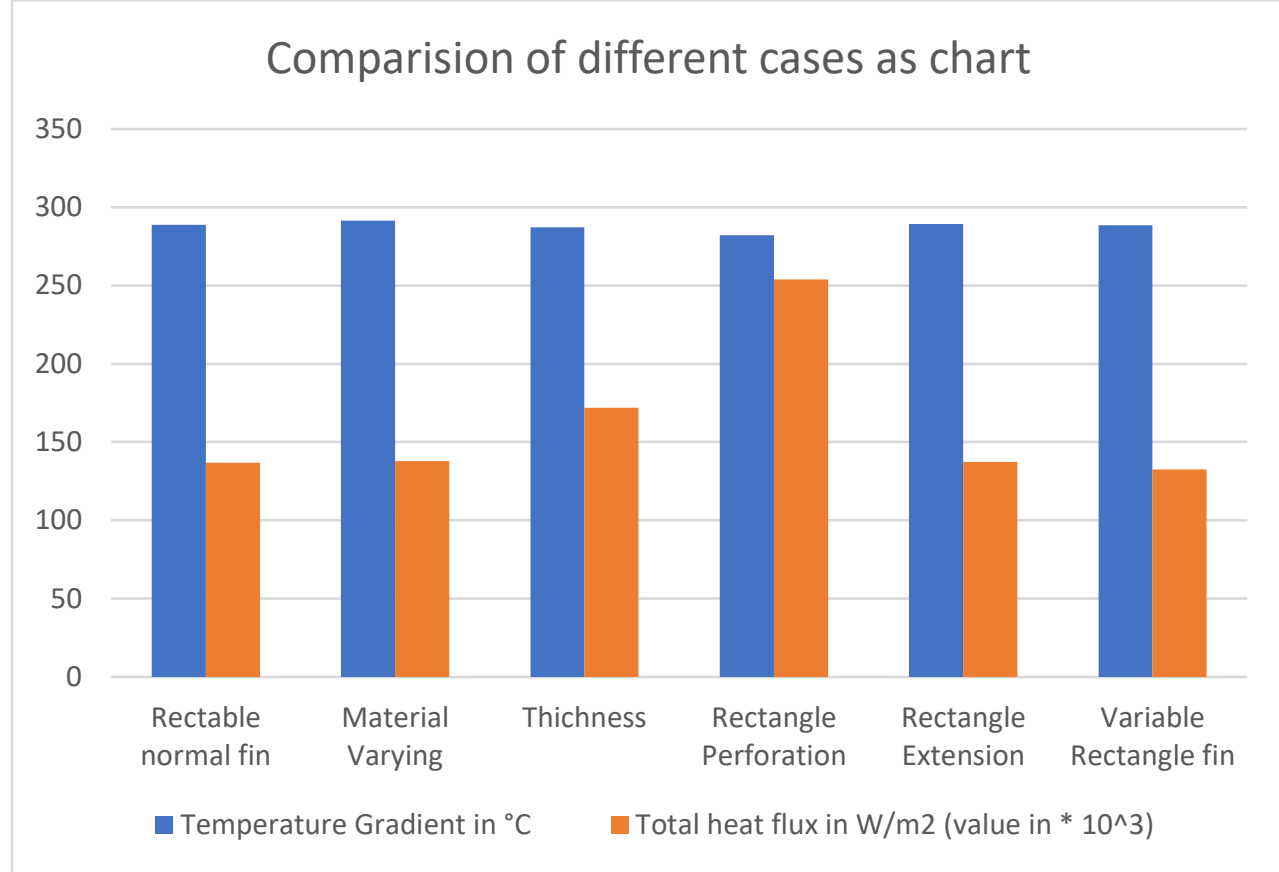

Chart 1: - Comparison of all rectangular fins

\section{COMPARISON}

-According to the result, the increment of heat transfer rate in rectangular perforated fin is more than rectangular varying thickness fin and it is more than rectangular fin with varying material and it is more than rectangular fin with rectangle extension and it is more than rectangular normal fin, but rectangle variable fin is quite less than normal fin. 
- And the minimum temperature value of rectangular perforated fin is less than rectangular varying thickness fin and it is less than rectangle variable fin and in other cases like rectangular extension fin and rectangular varying material fin are quite more than normal fin.

\section{CONCLUSION}

In this work, a rectangular fin body of different cases is modelled using Catia. The original model is changed by changing the thickness of the fins. The thickness of the original model is $5 \mathrm{~mm}$, it has been reduced to $4 \mathrm{~mm}$ in varying thickness case. By reducing the thickness of the fins, the overall weight is reduced. And used material for fin body is Aluminium Alloy 6061. In this work, other material is considered Aluminium Alloy 1100. And rectangular perforation, rectangular extension and variable rectangular profile is taken. Thermal analysis is done for all cases. By observing the thermal analysis results, the overall heat flux is generated more in rectangular perforation fin. Hence, it is expected to be dissipating more heat from the surface and Temperature at the end of fin with rectangular perforation is minimum as compare to fin with other cases. And the weight of the fin also can minimize and even minimum temperature of rectangular fin with varying material and rectangular fin with rectangle extension are quite more, but they offer better heat transfer than normal fin. And rectangular variable fin heat transfer is less than normal fin, but it offers minimum temperature at the end of the fin. So, overall every other case of rectangular fins offers results than normal rectangular fin it may be in terms of heat transfer coefficient or minimum temperature.

\section{Future scope}

Future scope of the project is to implement perforated type of fins to get better heat transfer rates and has to work on varying the better material which gets minimum temperature at the end of the fin with same standard dimensions. And in future wavy type and streamline type fins can study or analyze to get better velocity floe and pressure distribution.

\section{REFERENCES}

1. Design and analysis of different types of fin configurations using ANSYS. L.Prabhu, M.Ganesh Kumar, Prasanth M, Parthasarathy M International Journal of Pure and Applied Mathematics Volume 118 No. 5 2018, 1011-1017 ISSN: 1311- 8080 (printed version); ISSN: 1314-3395 Special Issue .

2. Experimental study on the effect of perforations shapes on vertical heated Fin performance under forced convection heat transfer. International Journal of Heat and Mass Transfer 118 (2018) 832Đ846 Nov2017

3. Design and Analysis for Heat Transfer through Fin with Extensions Pardeep Singh, Harvinderlal, Baljit Singh Ubhi International Journal of Innovative Research in Science, Engineering and Technology (An ISO 3297: 2007 Certified Organization )Vol. 3, Issue 5, May 2014

4. “G. Babu, M. Lavakumar", Heat Transfer Analysis and Optimization of Engine Cylinder Fins of Varying Geometry and Material in IOSR Journal of Mechanical and Civil Engineering (IOSR-JMCE), Volume-7, Issue-4 (Jul. - Aug. 2013), PP 24-29 .

5. "S.Jamala Reddy, Y.Tejeswar", Design and Thermal Analysis of Cooling Fins by Varying its Geometry and Material in International journal of Advanced Technology and Innovative Research of ISSN 2348-2370 Volume-07,Issue-05, June-2015, Pages:06280630 .

6. Abdullah, H. Alessa and Mohammed, Q. Al-Odat, "Enhancement of Natural Convection Heat Transfer from a Fin by Triangular Perforations of Bases Parallel and Toward its Base", The Arabian Journal for Science and Engineering, vol. 34, pp. 531-544, 2009.

7. Thermal Engineering by R.K. Rajput. 